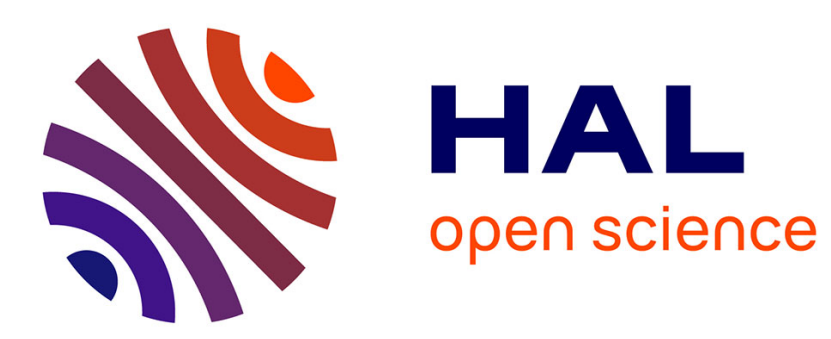

\title{
Analysis of Mechanical Loss Spectra in Zirconia Ceramics by Appying the Coupling Model
}

\author{
G. Haneczok, M. Weller
}

\section{To cite this version:}

G. Haneczok, M. Weller. Analysis of Mechanical Loss Spectra in Zirconia Ceramics by Appying the Coupling Model. Journal de Physique IV Proceedings, 1996, 06 (C8), pp.C8-703-C8-706. 10.1051/jp4:19968153 . jpa-00254587

\section{HAL Id: jpa-00254587 https://hal.science/jpa-00254587}

Submitted on 1 Jan 1996

HAL is a multi-disciplinary open access archive for the deposit and dissemination of scientific research documents, whether they are published or not. The documents may come from teaching and research institutions in France or abroad, or from public or private research centers.
L'archive ouverte pluridisciplinaire HAL, est destinée au dépôt et à la diffusion de documents scientifiques de niveau recherche, publiés ou non, émanant des établissements d'enseignement et de recherche français ou étrangers, des laboratoires publics ou privés. 


\title{
Analysis of Mechanical Loss Spectra in Zirconia Ceramics by Appying the Coupling Model
}

\author{
G. Haneczok and M. Weller* \\ Institute of Physics and Chemistry of Metals, Silesial University, 40-007 Katowice, Poland \\ * Max-Planck Institut für Metallforschung, Institut für Werkstoffwissenschaft, Seestrasse 92, \\ 70174 Stuttgart, Germany
}

\begin{abstract}
Mechanical loss spectra (two peaks) observed in $\mathrm{ZrO}_{2}$ doped with $\mathrm{Y}_{2} \mathrm{O}_{3}(2-10 \mathrm{~mol} \%)$, are attributed to oxygen vacancy (V)-yttrium $(\mathrm{Y}$ ) associates (V-Y pairs and $\mathrm{V}-2 \mathrm{Y}$ agglomerates). Both peaks were analysed numerically by applying the coupling model. It has been shown that: $i$ ) the activation enthalpy $H$ for both peaks increases with $\mathrm{Y}_{2} \mathrm{O}_{3}$ content, ii) the values of coupling parameter $\mathbf{n}$ are about $0.6-0.7$, iii) the activation enthalpy $\mathrm{H}_{0}$ corresponding to the noninteracting system (dilute case) is about $0.4 \mathrm{eV}$ which is considerably smaller than the activation enthaipy for reorientation of isolated dipoles $(0.8-0.9 \mathrm{eV})$
\end{abstract}

\section{INTRODUCTION}

It is well-known that interaction among diffusing species (e.g. point defects) in solids manifests itself as a broadening of loss maxima (mechanical or dielectric) compared with ideal Debye peaks for noninteracting systems (dilute case). With increasing defects concentration the experimentally observed broadening is usually accompanied by a shift of the loss maxima towards higher temperatures (or lower frequencies) and by an increase of the activation enthalpy of the relaxation process [1-9].

These interaction effects can be accounted for by the coupling model which describes the dynamics of relaxation processes in strongly correlated systems. According to this model the jump transition rate of the diffusing defects to neighbouring sites is time dependent for sufficient long time. As a consequence the relaxation function (static response function) takes a stretched exponential form, which is also known in literature as a universal response function $[1,10,11]$. The activation enthalpy of the relaxation process is affected by correlation effects and depends on the concentration of interacting defects. As was shown in [11] the stretched exponential function corresponds to a broad continuous distribution of relaxation times describing the experimentally observed shift and broadening of the loss spectra. Applicability of the coupling model to many interacting systems ( like polymers, glasses etc.) has been demonstrated in the past [1]. Recently this model was applied to the Snoek-Köster relaxation by taking into account the interaction between interstitial atoms into the Cottrell atmosphere [12].

In the case of relative weak interactions among diffusing species, as it has been already demonstrated for the Snoek relaxation in bcc metals [13-15], the correlation effects do not play a significant role and the activation enthalpy does not depend on the defects concentration. All features of the observed phenomena (i.e. the shift towards higher temperatures and the broadening of the Snoek peak) are well described by the model with random distribution of interaction energies between elastic dipoles.

The aim of this paper is to test the applicability of the coupling model for the description of the anelastic relaxations in yttria stabilised zirconia oxide. In $\mathrm{ZrO}_{2}$ doped with $\mathrm{Y}_{2} \mathrm{O}_{3}(2-10 \mathrm{~mol} \%)$ one oxygen vacancy (V) is formed for every two $\mathrm{Y}$ ions for charge compensation. The pair V-Y represents an elastic as well as a dielectric dipole. The vacancy is sited in one of the eight nearest neighbour positions of the dopant ion (see fig.6 in [3]). The defect symmetry is trigonal as the dipole axis lies in $<111>$ direction [2-6]. Reorientation of the dipole under an external applied field (electric or elastic) may occur by jumping of the vacancy around the dopant ion.

Mechanical loss spectra of yttria stabilised zirconia (3-10 mol\% $\mathrm{Y}_{2} \mathrm{O}_{3}$ ) consist of two maxima which are attributed to thermally activated reorientation of V-Y pairs (the peak at lower temperatures denoted as I) and complexes of type V-2Y (the peak at higher temperatures denoted as $I_{A}$ ) $[3,7,9]$. It was shown that 
the activation enthalpy for reorientation of V-Y pairs increases with yttria content [7] and also that both peaks are much broader than a single Debye relaxation (2-4 times) [3,9]. These effects are expected for a strong interacting defect system and should be described by the coupling model.

\section{EXPERIMENTAL RESULTS}

The experimental data were obtained for samples of tetragonal zirconia polycrystals (TZP) with 2 and 3 $\mathrm{mol} \% \mathrm{Y}_{2} \mathrm{O}_{3}$ and also for crystals of cubic stabilised zirconia (CSZ) with $10 \mathrm{~mol} \% \mathrm{Y}_{2} \mathrm{O}_{3}$ ([110] orientation of the longitudinal axis). Details on sample preparation are described in [6-8] and [3].

Mechanical loss measurements were carried out with two types of apparatus by using the same samples. Low frequency measurements were performed with inverted torsion pendulum with oscillation frequencies ranging from $2-15 \mathrm{~Hz}$. High frequency measurements in the $\mathrm{kHz}-$ range were performed by exciting the specimens in eigenvibrations. Fig.1 represents mechanical loss curves obtained with the low frequency torsion pendulum $(\mathrm{f} \approx 2 \mathrm{~Hz})$. For lower $\mathrm{Y}_{2} \mathrm{O}_{3}$ contents the mechanical spectrum shows one maximum - I. With increasing yttria content this maximum shifts towards higher temperatures and the second peak $\left(\mathrm{I}_{\mathrm{A}}\right)$ appears at about $500 \mathrm{~K}$. For high frequency measurements the loss spectra exhibit similar variations with yttria content as presented in figure 1 .

\section{ANALYSIS BY APPLYING THE COUPLING MODEL}

The elastic energy loss curve (loss tangent) $Q^{-1}(T)$ according to the coupling model can be written in the form [11]:

$$
Q^{-1}=\omega \Delta \int_{0}^{\infty} \exp \left[-(t / \tau)^{1-\mathrm{n}}\right] \cos (\omega t) d t
$$

where $\omega$ is the angular frequency, $\Delta$ denotes the relaxation strength, $\tau$ the relaxation time corresponding to the interacting system, $n$ the coupling parameter $(0<\mathrm{n}<1)$ describing the degree of correlation of the system. The relaxation time $\tau$ obeys an Arrhenius equation of the form:

$$
\tau=\tau_{\infty} \exp (\mathrm{H} / \mathrm{kT})
$$

where $\tau_{\infty}$ is the preexponential factor, $H$ the activation enthalpy, $\mathrm{k}$ the Boltzmann constant. The activation enthalpy $\mathrm{H}$ reflects the interaction effects via many body correlations and can be expressed as:

$$
\mathbf{H}=\mathbf{H}_{0} /(1-\mathbf{n})
$$

where $\mathrm{H}_{0}$ is the activation enthalpy describing the noninteracting system which in practice corresponds to a dilute case. If $n=0$ the correlation effects are neglected, $\mathrm{H}=\mathrm{H}_{0}$ and eq.(1) takes the form of a single Debye curve. If $n>0$ the correlation effects play a significant role and $H$ increases in relation to $H_{0}$, but the product $H(1-n)$ should be constant.

In order to perform the quantitative analysis of the experimental data by applying the coupling model, the non-linear regression procedure was used [16]. The model function defined by eq.(1) together with eq.(2) for $\tau$, contains four parameters: $\Delta, H, n$ and $T_{p}$. The peak temperature $T_{p}$ corresponds to the condition $\omega \tau=1$ (it is convenient to insert $T_{p}$ as a fitting parameter instead of $\tau_{\infty}$ from eq.(2)). In the case of two loss maxima the model function is taken as a sum of two independent components given by eq.(2). The correctness of the calculations and the fit quality may be judged by two criteria: i) the activation enthalpy values $\mathrm{H}$ obtained from fitting the individual $\mathrm{Q}^{-1}(\mathrm{~T})$ curve (denoted as $\mathrm{H}_{\mathrm{fit}}$ ) should agree with the value of $\mathrm{H}_{\mathrm{fs}}$ calculated from the frequency shift between the fitting parameters $\mathrm{T}_{\mathrm{p}}$ for curves measured at different frequencies, ii) the value of the product $\mathrm{H}_{\mathrm{fit}}(1-n)$ should be independent on yttria content.

As the first attempt it was assumed that $\mathrm{Q}^{-1}(\mathrm{~T})$ curves obtained for $2 \mathrm{Y}-\mathrm{TZP}$ and $3 \mathrm{Y}$-TZP consist of one single loss peak (I). Fig.2 shows the experimental data for 2Y-TZP and the theoretical curve calculated according to eq.(1) for one process. From this figure it can be recognised that the quality of the fit is not good enough. This indicates that the second peak $\left(\mathrm{I}_{\mathrm{A}}\right)$ is already present in samples with lower $\mathrm{Y}_{2} \mathrm{O}_{3}$ concentrations. According to this result all measured spectra were analysed with the assumption that both 
peaks $\left(\mathrm{I}\right.$ and $\mathrm{I}_{\mathrm{A}}$ ) were present for all $\mathrm{Y}_{2} \mathrm{O}_{3}$ content. The results of this analysis are listed in Table 1 and presented in Figs.3 and 4.

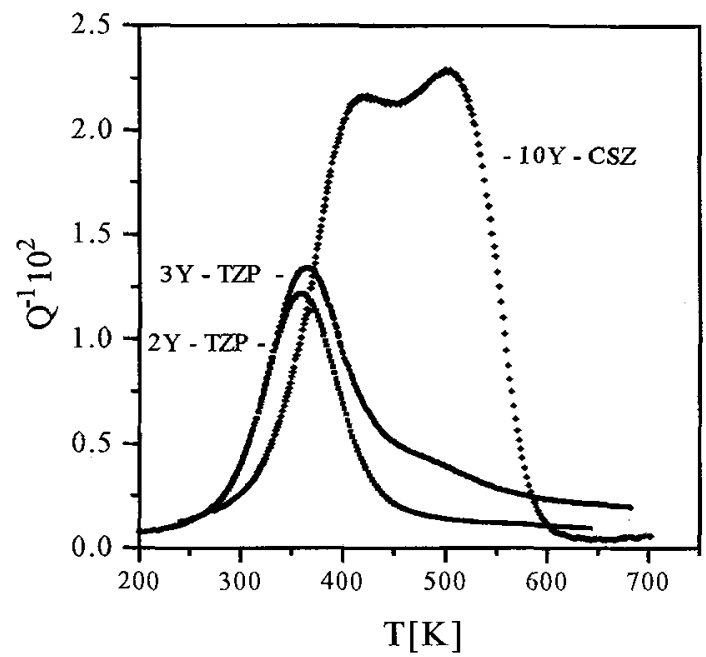

Fig. 1 Experimental data obtained in low frequency range.

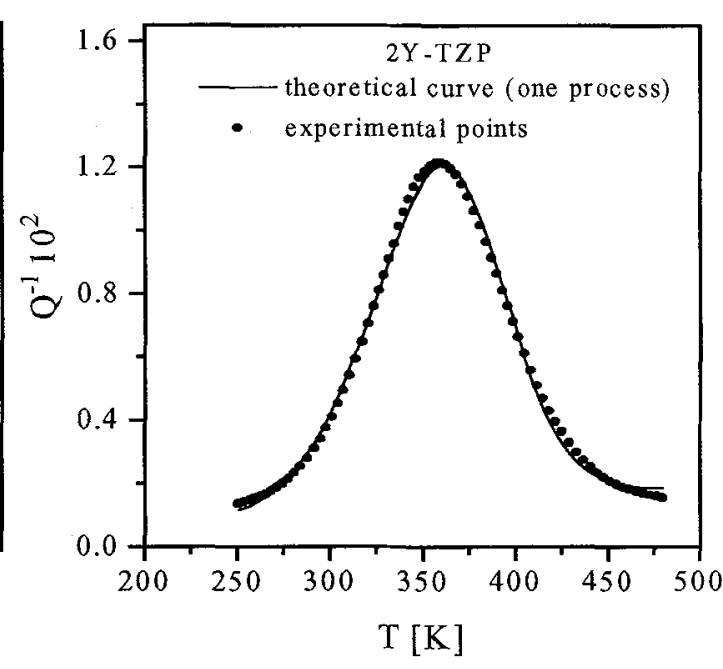

Fig.2 Results of the preliminary numerical analysis.

Table 1. Activation enthalpies $H_{\mathrm{fit}}, H_{\mathrm{fs}}$, coupling parameter $n$, values of $H_{0}=(1-n) \mathrm{H}_{\mathrm{fit}}$ obtained by applying the coupling model for peak $\mathrm{I}$ and peak $\mathrm{I}_{\mathrm{A}}$ for different concentration of $\mathrm{Y}_{2} \mathrm{O}_{3}$.

\begin{tabular}{|c|c|c|c|c|c|c|c|c|c|}
\hline \multirow[t]{2}{*}{$\mathrm{Y}_{2} \mathrm{O}_{3}[\mathrm{~mol} / \mathrm{0}]$} & \multirow[t]{2}{*}{$\mathrm{f}[\mathrm{Hz}]$} & \multicolumn{4}{|c|}{ peak I } & \multicolumn{4}{|c|}{ peak $I_{A}$} \\
\hline & & $\mathrm{H}_{f_{f t}[\mathrm{eV}]}$ & $\mathrm{H}_{\mathrm{f}}[\mathrm{eV}]$ & $\mathrm{n}$ & $(1-n) \mathrm{H}_{\text {fit }}$ & $\mathrm{H}_{\mathrm{f}}[\mathrm{eV}]$ & $\mathrm{H}_{\mathrm{f}}[\mathrm{eV}]$ & $\mathrm{n}$ & $(1-n) \mathrm{H}_{0}$ \\
\hline \multirow[t]{2}{*}{2} & 2.72 & 0.89 & \multirow[t]{2}{*}{0.90} & 0.60 & 0.36 & 1.11 & \multirow[t]{2}{*}{1.11} & 0.56 & 0.49 \\
\hline & 2070 & 0.92 & & 0.56 & 0.40 & 1.14 & & 0.70 & 0.34 \\
\hline \multirow[t]{2}{*}{3} & 2.52 & 0.92 & \multirow[t]{2}{*}{0.92} & 0.61 & 0.36 & 1.25 & \multirow[t]{2}{*}{1.25} & 0.76 & 0.30 \\
\hline & 2230 & 0.91 & & 0.58 & 0.39 & 1.25 & & 0.62 & 0.48 \\
\hline \multirow[t]{2}{*}{10} & 1.76 & 1.21 & \multirow[t]{2}{*}{1.21} & 0.69 & 0.38 & 1.88 & \multirow[t]{2}{*}{1.93} & 0.72 & 0.53 \\
\hline & 2650 & 1.21 & & 0.62 & 0.46 & 1.88 & & 0.61 & 0.72 \\
\hline
\end{tabular}

\section{DISCUSSION AND CONCLUSIONS}

From Table 1 it can be recognised that the two criteria (i) and (ii) of the previous section are well fulfilled. Values of the activation enthalpy $\mathrm{H}_{\mathrm{fit}}$ and $\mathrm{H}_{\mathrm{fs}}$ are equal within error limits $(0.02-0.03 \mathrm{eV})$. For both peaks ( $\mathrm{I}$ and $\mathrm{I}_{\mathrm{A}}$ ) $\mathrm{H}_{\mathrm{fi}}$ as well as $\mathrm{H}_{\mathrm{f}}$ increase with increasing $\mathrm{Y}_{2} \mathrm{O}_{3}$ content. In the first approximation this increase is linear and fulfils the relations:

$$
\text { peak I: } \mathrm{H}[\mathrm{eV}]=0.81+0.04 \mathrm{c}[\mathrm{mol} \%] ; \quad \text { peak } \mathrm{I}_{\mathrm{A}}: \quad \mathrm{H}[\mathrm{eV}]=0.93+0.1 \mathrm{c}[\mathrm{mol} \%]
$$

The values of $\mathrm{H}_{0}=(1-n) \mathrm{H}_{\text {fit }}$ are also approximately constant. This criterion is much better fulfilled for peak $\mathrm{I}$. The mean values of $\mathrm{H}_{0}$ are $0.40 \pm 0.03 \mathrm{eV}$ and $0.5 \pm 0.1 \mathrm{eV}$ for peak $\mathrm{I}$ and $\mathrm{I}_{\mathrm{A}}$, respectively.

According to the coupling model $\mathrm{H}_{0}$ is the activation enthalpy of the relaxation process for $n=0$, corresponding to the dilute case where the correlation effects do not play any role. In the case of the stabilised $\mathrm{ZrO}_{2}$ the dilute case does not exist since the doping is required for stabilisation. Independent of that one can compare the obtained value of $\mathrm{H}_{0}$ with the value of the activation enthalpy determined from eq. (4) for $\mathrm{c}=0$ which is $\mathrm{H}=0.8-0.9 \mathrm{eV}$. Evidently the obtained $\mathrm{H}_{0}$ values are about two times smaller than the expected values from eq.(4). 


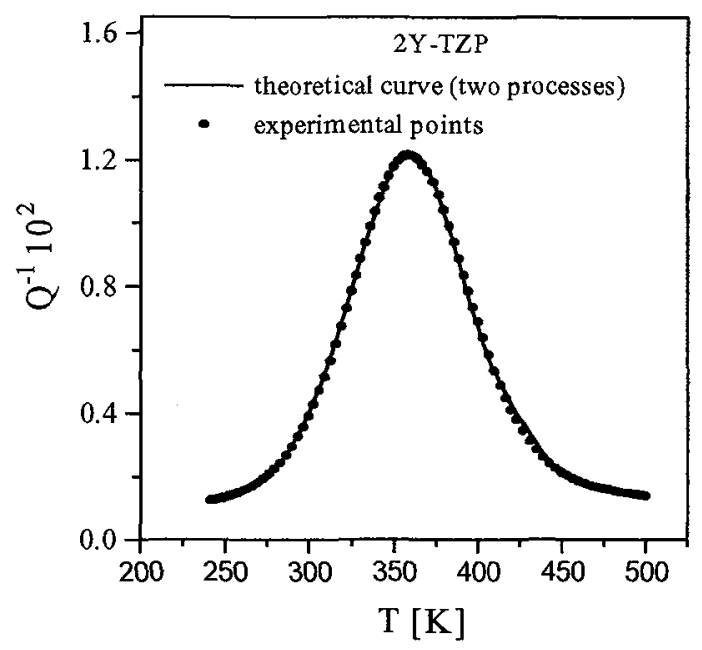

Fig. 3 Results of the numerical analysis for $2 Y-T Z P$.

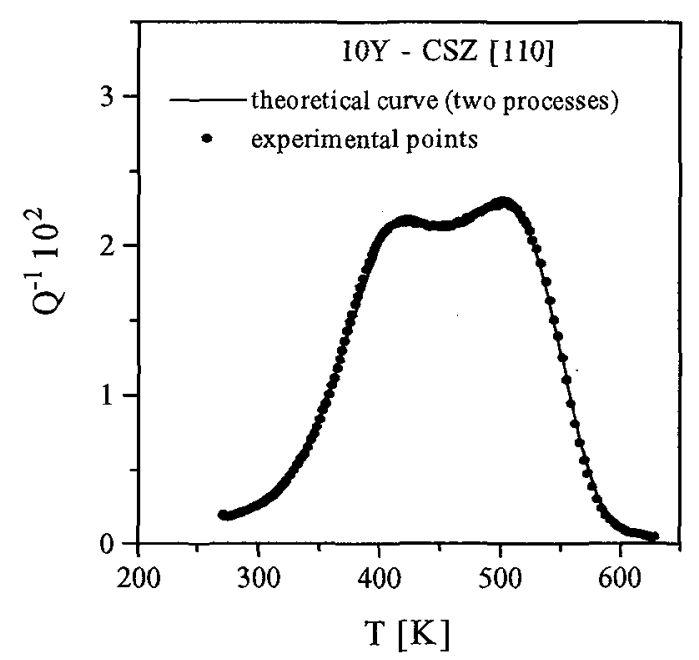

Fig.4 Results of the numerical analysis for $10 \mathrm{Y}-\mathrm{CSZ}$.

This disagreement is difficult to explain in the frame of the coupling model. The parameter $\mathrm{n}$ describing the broadening of the loss maxima has to be high enough because the measured spectra are $2-4$ times broader than a single Debye peak. According to eq.(3) the high values of $n(0.6-0.7)$ correspond to small values of $\mathrm{H}_{0}$. In our opinion it could be explained by assuming that additionally the activation enthalpy for thermal reorientation of the V-Y pairs (and also V-2Y) is distributed itself. As a consequence, the values of the parameter $\mathbf{n}$ obtained in this paper are overestimated and the value of $\mathrm{H}_{0}$ has no physical meaning. The verification of this hypothesis requires however additional examinations.

The main results from the analysis of mechanical loss spectra in zirconia ceramics made by applying the coupling model are the following: i) the activation enthalpy for both peaks $I$ and $\mathrm{I}_{\mathrm{A}}$ increases with $\mathrm{Y}_{2} \mathrm{O}_{3}$ content, ii) the values of the coupling parameter $\mathrm{n}$ are about $0.6-0.7$, iii) the activation enthalpy $\mathrm{H}_{0}$ corresponding to the noninteracting system (dilute case) is about $0.4 \mathrm{eV}$. This value is about two times smaller than the activation enthalpy for reorientation of dipoles in dilute $\mathrm{ZrO}_{2}-\mathrm{Y}_{2} \mathrm{O}_{3}(0.8-0.9 \mathrm{eV})$.

\section{Acknowledgements}

One of the authors (M.W.) is indebted to the Deutsche Forschungsgemeinschaft for financial support.

\section{References:}

[1] K.L.Ngai, in Disorder Effects in Relaxation Processes, ed.A.Blumen, Springer Verlag, Berlin 1994.

[2] A.S.Nowick, in Diffusion in Crystalline Solids, Academic Press, N.Y. 1984, p.143-165.

[3] M.Weller, Z.Metallkd.,84 (1993) 381-386.

[4] M.P.Anderson, A.S.Nowick, J.de Phys.,42 (1981) 823-829.

[5] D.Y.Wang, A.S.Nowick, J.Phys.Chem.Solids,44 (1983) 639-653.

[6] M.Weller, H.Schubert, J.Am.Ceram.Soc.,69 (1986) 573-577.

[7] M.Weller, H.Schubert, Solid State Ionics, ed. Balkanski etc.,Elsevier Science Publ. 1992, p.569-574.

[8] M.Weller, H.Schubert, D.D.Upadhyaya, in Electroceramics IV, Vol II, ed.R.Waser etc., Verlag der Augustinus. Buchhandlung., Aachen 1994, p.853-856.

[9] M.Weller, J. of Alloys and Compounds, 211/212 (1994) 66-70.

[10] K.Funke, Berichte Bunsenges Phys.Chem.,95 (1991) 955-964.

[11] E.W.Montroll, J.T.Bendler, J. of Statistical Physics, 34 (1984) 129-162.

[12] Y.Wang, M.Gu,L.Sun, K.L.Ngai, Phys.Rev.B 50 (1994) 3525-3531.

[13] M.Weller, G.Haneczok, J.Diehl, Phys.Stat.Sol(b), 172 (1992) 145-159.

[14] G.Haneczok, M.Weller, J.Diehl, Phys.Stat.Sol.(b),172 (1992) 557-571.

[15] G.Haneczok, M.Weller, J.Diehl, J. of Alloys and Compounds, 211/212 (1994) 71-74.

[16] G.Haneczok, M.Weller, J. Less. Common Met.,159 (1990) 169-176. 